\title{
4 Gender and adaptive collaborative management in forested Ugandan landscapes
}

\author{
Allan Bomuhangi, Abwoli Yabezi Banana, \\ Jimmy Bushoborozi, Concepta Mukasa, \\ Alice Tibazalika and Esther Mwangi
}

\section{Introduction}

While the concept of participation has been a part of development thinking and the political process for the last two decades, today it has become mandatory for planning any natural resource management and development project. Participation is viewed by development scholars and practitioners as a crucial element in enabling poor and marginalized groups to exert greater influence over institutions and decisions that critically affect their lives.

In forestry, participation has been promoted through approaches such as collaborative forest management and/or adaptive collaborative management where decision making by forest adjacent communities in making rules related to enforcement and benefit sharing has been formally acknowledged by the state (Mukasa et al. 2016). Developing countries adopt varied participatory approaches (Banana et al. 2013). Despite design differences, they all aim to ensure better forest governance and management as well as improved livelihoods. However, the question of who participates and why remains critical for those interested in sustainable forest management. The Government of Uganda has undergone reforms since the late 1990s, most of which have recognized gendered issues and the importance of people's participation in the management of development programmes. In 2016, the Ministry of Water and Environment developed the "Environment and Natural Resources Subsector Gender Mainstreaming Strategy, 2016-2021" to reduce unsustainable environmental resource management as well as reduce poverty resulting from inequalities in environmental resource use, access and management (GoU 2016).

In the forestry subsector, Uganda has developed different forest management regimes, with each regime having different effects on user communities and on gender (Banana et al. 2012, 2013; Mukasa et al. 2016). Although Uganda's forest policy highlights the need to ensure the integration of gender concerns and issues into the development of the forest sector, the National Forestry and Tree Planting (NFTP) Act does not provide measures to enforce the gender intentions of the policy; consequently, neither the National Forestry Authority (NFA) nor the Forest Sector Support Department (FSSD) 
has any guidelines on how to mainstream gender in their respective programmes and activities (GoU 2001). The forestry subsector's specific strategies highlighted in the Environment and Natural Resources Subsector Gender Mainstreaming Strategy for the NFA and the FSSD have not been fully adopted (GoU 2016). Consequently, men still dominate the arena of planning and decision making regarding the use, access and management of forest resources, and women's views are often under-represented, implying that women's practical and strategic needs may not be addressed. Women's involvement in forest management and development - such as we see here - has been identified as crucial in achieving Sustainable Development Goal 5 (Lee et al. 2016). Better progress can be made towards this goal if participatory forest management initiatives such as ACM are institutionalized and implemented throughout the country.

In the mid-2010s, we applied CIFOR's adaptive collaborative management approach $(\mathrm{ACM})^{1}$ across several districts in Uganda to strengthen women's rights to forest and tree resources and to increase their participation and leadership in forest decision making (Mukasa et al. 2016; see also Chapter 5, this volume, where Mukasa et al. highlight the governance arrangements, practices and processes that are central to enhancing gender inclusion and the transformation of underlying values and norms in community forestry). Here, we discuss the results of a nationwide study looking at the gender gap in participation and representation in community forestry; we specifically examine the determinants and quality of men's and women's participation in forest management, gendered use of forest resources and factors that influence dependence on forestry resources. Although our initial emphasis was on women's involvement in forest management, we later realized we could analyse our data to assess the effectiveness of ACM in this regard by comparing ACM versus non-ACM sites. Here, we consider the policy implications of whether participatory forest management approaches such as ACM can help reduce the gender gap in forest management and decision making.

\section{Methodology}

\section{Study area and sampling}

We conducted a nationwide intra-household survey in 2016 to ensure that findings would be broadly relevant for different forest management regimes in Uganda and provide a robust basis for national/regional-level policymaking. Study sites were purposively selected to maximize sub-national variation in socio-cultural and ecological conditions. The survey covered eight districts of Uganda located in various regions of the country (Figure 4.1) and across four agro-ecological zones: Albertine Rift and Afromontane agro-ecological zones in western Uganda; the Lake Victoria basin in central Uganda; the Aswa river plain in northern Uganda; and the short grasslands agro-ecological zone in eastern Uganda. 


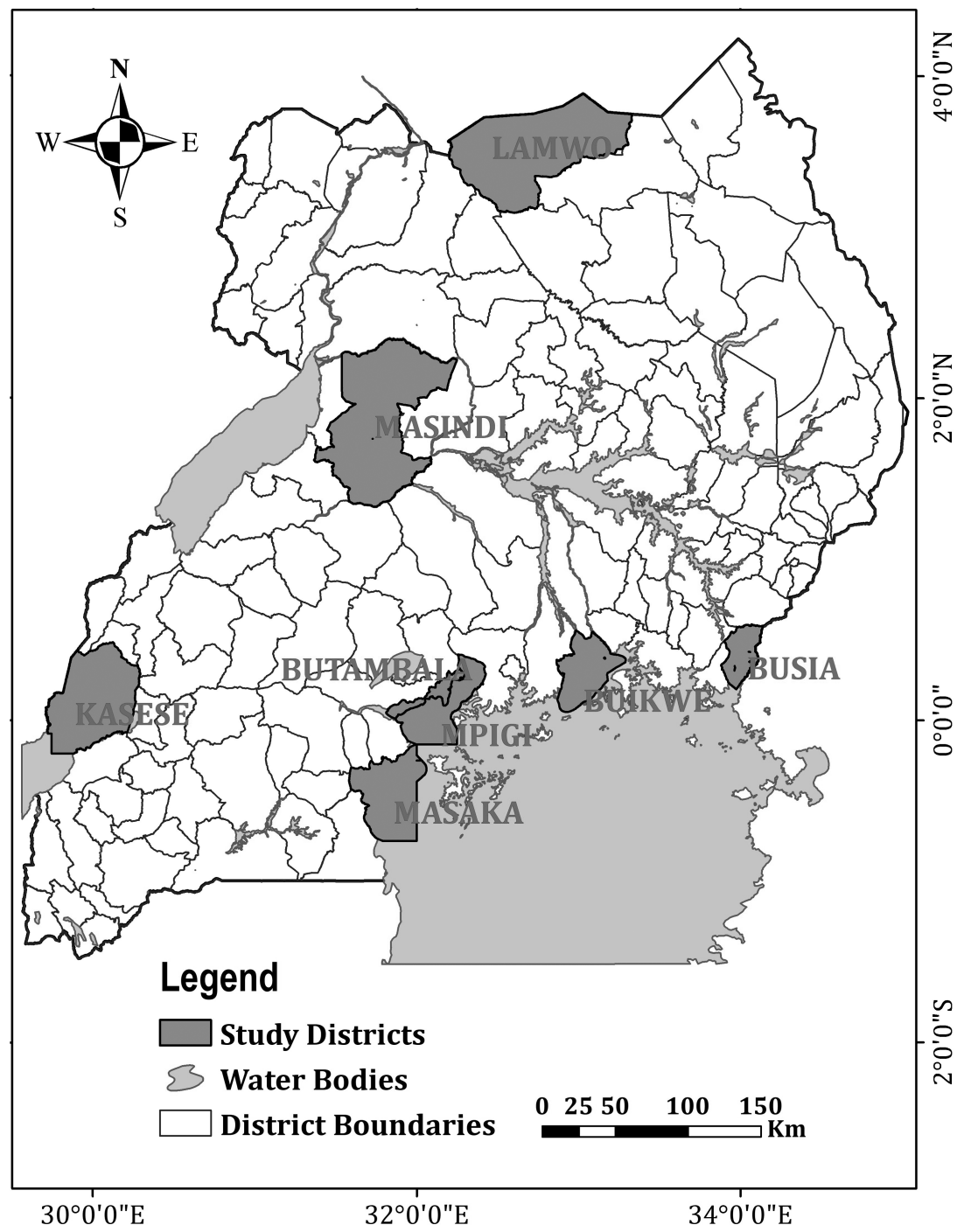

Figure 4.1 Study sites.

The Lake Victoria basin in central Uganda with six sites (including four ACM sites with an ethnically homogenous population and two ACM sites with ethnically heterogeneous populations) is dominated by tropical high forests and forest plantations under multiple tenure regimes and several forest governance arrangements (see Table 4.1). The region is also densely populated with primarily the Baganda and Basoga ethnic groups. The Afromontane region in western Uganda, with four sites (including two ACM sites), is 


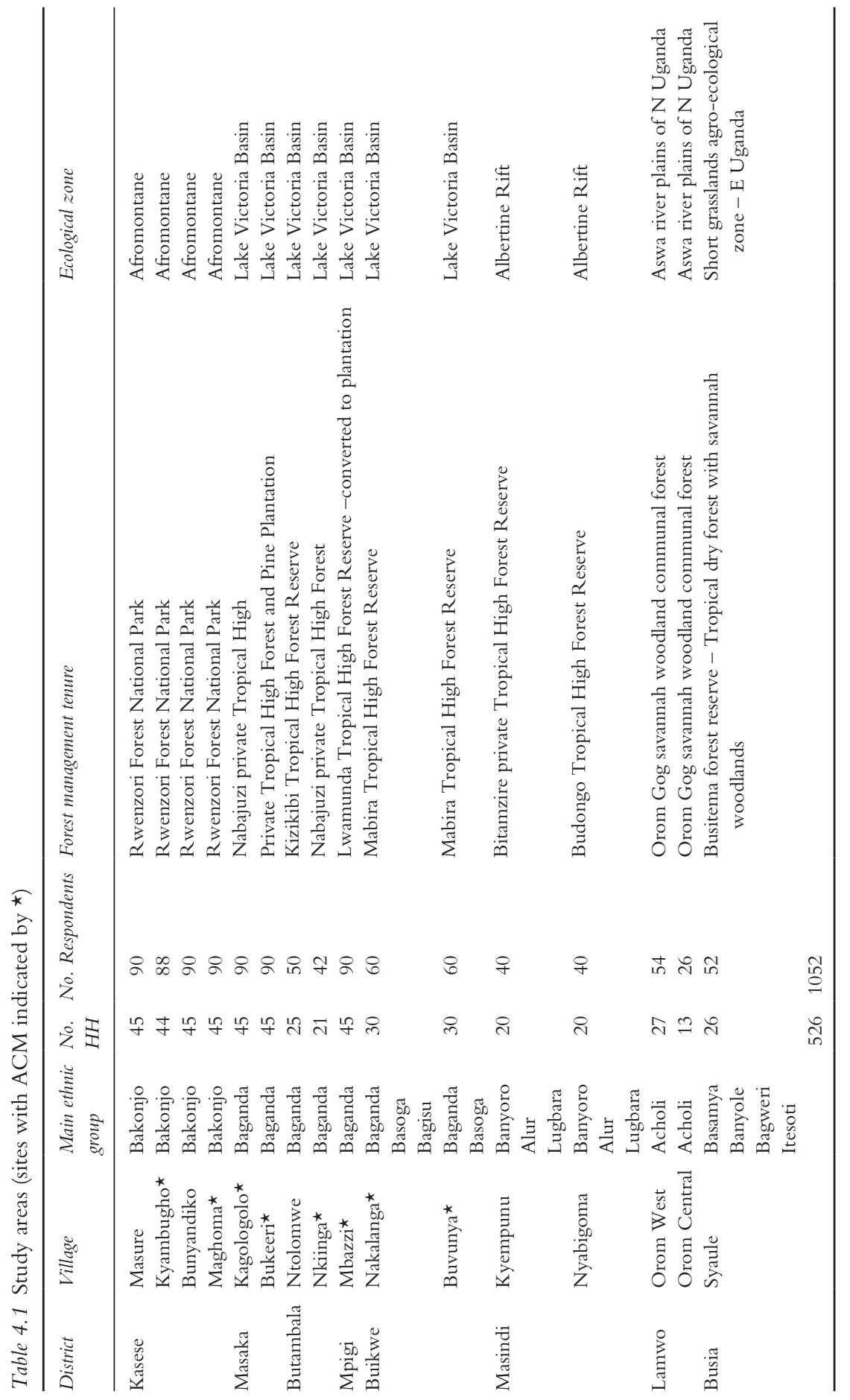


dominated by the Rwenzori Forest National Park and the Bakonzo ethnic group. The two sites in the Albertine Rift in western Uganda are dominated by tropical high forests under state or private governance arrangements. The region is sparsely populated with several ethnic groups. The Aswa river plain of northern Uganda, with two sites, is dominated by savannah woodlands under customary governance arrangements. The region is sparsely populated with the Acholi ethnic group. The one site in the short grasslands agro-ecological zone of eastern Uganda is dominated by grasslands and few forests; it is densely populated with the Basamya, Banyole, Itesoti and Bagweri ethnic groups. ACM was conducted with Bakonjo, Baganda and Basoga peoples, with one site, in Mabira Forest, including some Bagisu. To understand the impact of forest tenure on women's participation in forests, we purposively selected multiple tenure regimes, including private and communal forests, as well as forests officially managed by different government agencies implementing co-management arrangements with adjacent or resident communities (Table 4.1).

Our study focused on 16 communities (eight with ACM) in these eight districts. Although the pairing of ACM and non-ACM sites was not possible, given travel and funding constraints, there are ACM sites located in five of these eight districts, providing reasonable geographic and ethnic distribution. Many demographic similarities (shown in Table 4.2) further support the legitimacy of comparing ACM and non-ACM responses.

We compiled a list of households residing in each selected study community, drawing upon information from village registers and lists provided by village leaders. Households were randomly selected from the village register. A total of 526 households were selected, and 1,052 respondents were interviewed (526 men and 526 women). Husband and wife were interviewed separately to generate broader-scale information on the following issues: factors that affect men's and women's participation in forest management; the quality of their participation; gendered forest use; perceptions on the abundance of forest

Table 4.2 Demographic characteristics of the respondents

\begin{tabular}{|c|c|c|c|c|c|c|c|c|}
\hline \multirow[t]{3}{*}{ Name of variable } & \multicolumn{4}{|c|}{ ACM sites } & \multicolumn{4}{|c|}{ Non-ACM sites } \\
\hline & \multicolumn{2}{|l|}{ Men } & \multicolumn{2}{|c|}{ Women } & \multicolumn{2}{|l|}{ Men } & \multicolumn{2}{|c|}{ Women } \\
\hline & Mean & $\begin{array}{l}\text { Standard } \\
\text { deviation }\end{array}$ & Mean & $\begin{array}{l}\text { Standard } \\
\text { deviation }\end{array}$ & Mean & $\begin{array}{l}\text { Standard } \\
\text { deviation }\end{array}$ & Mean & $\begin{array}{l}\text { Standard } \\
\text { deviation }\end{array}$ \\
\hline \multicolumn{9}{|l|}{ Age } \\
\hline $18-35$ & 17.5 & 13.8 & 23.5 & 18.5 & 18.4 & 15.3 & 25.5 & 20.4 \\
\hline $36-59$ & 17.5 & 10.7 & 8.1 & 7.3 & 18.8 & 11.2 & 10.4 & 9.7 \\
\hline 60 and above & 7.0 & 4 & 3.1 & 2.9 & 6.0 & 4 & 3.5 & 3 \\
\hline Education level (years) & 6.7 & 3.8 & 3.9 & 3.8 & 6.5 & 3.2 & 3.6 & 3.9 \\
\hline Household size (persons) & 8 & 4 & 8 & 4 & 8 & 4 & 8 & 4 \\
\hline Land size (acres) & 1.4 & 1.9 & 1.1 & 1.7 & 1.5 & 1.8 & 1.0 & 1.5 \\
\hline Distance to forest $(\mathrm{km})$ & 1.6 & 0.6 & 1.4 & 0.2 & 1.5 & 0.5 & 1.5 & 0.4 \\
\hline
\end{tabular}


resources; and factors that influence dependence on forest resources and gendered use of income from forest resources across ACM and non-ACM sites. For women-headed households, we interviewed men living in such households aged 18 years and above.

\section{Data analysis}

Descriptive statistics were used to portray the respondents' socio-economic characteristics, while cross-tabulations were used to generate Pearson chisquare $\left(\chi^{2}\right)$ values. The latter were used to test any association between the men's and women's quality of participation in forest management and dependence on forest products, as well as the use of forest income in ACM versus non-ACM sites. We used an alpha level of 0.05 for all statistical tests.

Factor analysis was used to identify latent dimensions underlying indicators that measured men's and women's participation in forest management. Ten participatory indicators (level of husband's support + education / years in school + participation in ACM + distance to forest + dependence on forest resource + position/status of women in community + ethnicity + household income + knowledge of laws and policy + marital status) were considered based on theory and related empirical work (Ostrom 1990; Araral 2009; Dolisca et al. 2006; Lise 2000; Maskey et al. 2006) to influence participation in forest management. Principal component analysis (PCA) was used to extract factors using varimax rotation to ensure that the extracted factors were independent and unrelated to each other and to maximize the loading on each variable and minimize the loading on other factors (Bryman and Cramer 2005). The number of significant factors was determined by calculating the eigenvalue (variance accounted for by each factor). Factors with eigenvalues exceeding 1.5 were considered significant following Kaiser's criterion (Kaiser 1974).

\section{Results and discussion}

Here, we begin with a discussion of the household characteristics of our respondents, which shows the similarities between the ACM and non-ACM communities. We then examine the issues we considered important, both in terms of "normal" practice (non-ACM) and as influenced by ACM activities.

\section{Household characteristics}

Household characteristics are important in explaining the behaviour of respondents in most studies. In this study, they help in explaining the factors that influence the participation of men and women in forest management activities in Uganda. The age of the respondents ranged from 18 to 60 and above in both ACM and non-ACM sites (Table 4.2). The respondents across both study sites were relatively middle aged with an average of 42.1 years for men and 34.7 years for women. The years of education ranged from 0 to 12, with an average 
of 6.65 years (men) and 3.75 years (women), indicating probable low levels of literacy among the study population. Girls in Uganda often drop out of school at an earlier age compared with boys. Households in the study sites had an average of eight persons. This is higher than the national average family size (five people per family; UBOS 2013). The size of landholding averaged 1.45 acres ( 0.59 hectares) according to men and 1.05 acres ( 0.42 hectares) according to women. Results across the sites also show the mean average of perceived distance to the forest as $1.6 \mathrm{~km}$ for men and $1.5 \mathrm{~km}$ for women. Interestingly, women reported relatively smaller sizes for the family's landholdings and shorter distances to the forest in comparison with their male counterparts.

\section{Men's and women's perceptions of their own participation in forest management in ACM versus non-ACM sites}

The study investigated the participation of women in public (community forest) versus private spaces (household farmland). In line with cultural norms, we expected that women would more likely be involved in decision making at the household level than in public. However, the results show that women rated their participation in forest management at the community level $(96 \%$ in ACM sites and $76.2 \%$ in non-ACM sites) to be higher as compared with participation at the household level $(72.4 \%$ in ACM sites and 52.2\% in nonACM sites; Table 4.3). Across both ACM and non-ACM sites, women perceived themselves to be more involved in establishing tree nurseries and tree planting at the community level than at the household level. In comparison, their male counterparts perceived themselves to be more involved overall at the household level as compared with the community level in both ACM (97.4\% to $86 \%$ ) and non-ACM sites (82\% to $78.2 \%)$. The results also reveal that men's and women's perceived participation in forest management activities was higher in ACM sites as compared with non-ACM sites, implying that participation in ACM enhanced their levels of inclusion in forest management activities. Qualitative results suggest that women perceived their communitylevel participation more highly because at that level, as participants in women's groups, they had more control of the proceeds from forest products sales. At home, their husbands controlled such proceeds.

This finding further builds on the argument that women's participation in forestry activities increased with the formation of groups and participation in ACM. A chi-square test of independence was performed to examine the relation between gender and participation of men and women in private versus public spaces. The relationship between these variables was significant. Women were more likely to engage in forest management activities in public forested spaces (community forests) as compared with their involvement in private forested spaces (household level): $\chi^{2}(4, \mathrm{~N}=526)=8.9, p=0.0032$. In contrast, men were more likely to engage in forest management activities at the household level as compared with their involvement at the community level: $\chi^{2}(4, \mathrm{~N}=526)=1.7, p=0.0043$. 
94 Allan Bomuhangi et al.

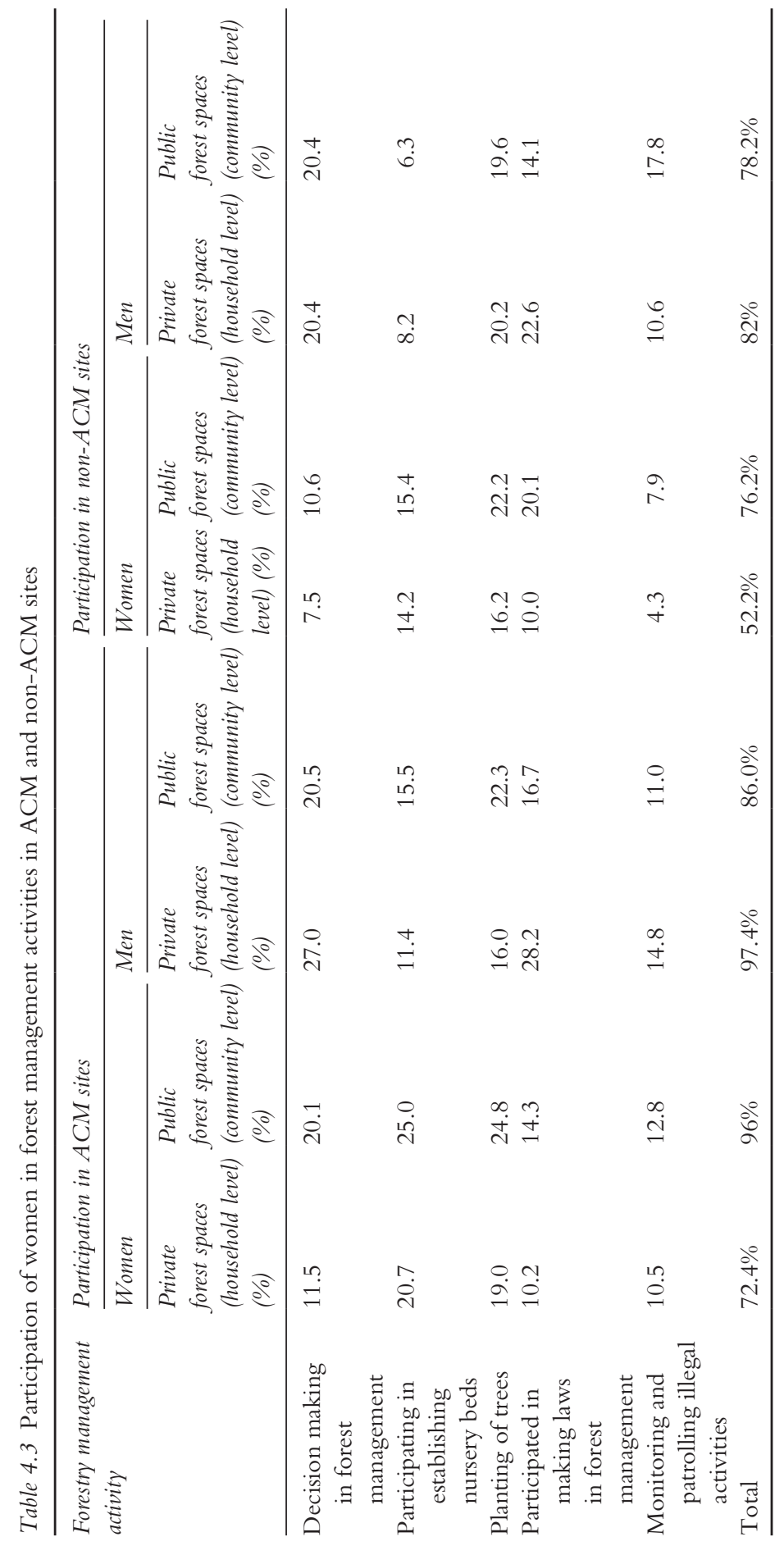




\section{Men's and women's perceptions of the quality of their own participation in forest management in ACM versus non-ACM sites}

Having established men's and women's perceptions of their own participation in forest management in ACM and non-ACM sites, we were also interested in how men and women rated the quality of their participation (Table 4.4). The a priori expectation was that if women evaluated their quality of participation as poor, this could indicate a host of reasons: for example, lack of involvement, discrimination (unintentional or active) and a perception that the forests are a man's concern. Contrary to expectation, descriptive statistics reveal that a substantial number of men (37\% in ACM sites and 46\% in non-ACM) considered their own quality of participation as poor. This number was slightly higher in comparison with the women who rated the quality of their participation as poor (25\% in ACM sites vs. $43 \%$ in non-ACM sites). This may well be related to cultural expectations that men should be involved in forest management, whereas there may be no such expectation for women. Interestingly, a slightly greater number of women (13\% in ACM vs. 3\% in non-ACM sites) reported that the quality of their own engagement was very good while only $6 \%$ of men in ACM sites versus 4\% in non-ACM sites reported the quality of their own participation as very good.

In our study, both men and women perceived their quality of participation in forest management in ACM sites as above average (63.8\%) as compared with their participation in non-ACM sites (33.1\%). Women's participation in ACM sites was rated better (25\% poor) as compared with $43.3 \%$ poor in non-ACM sites, implying that involvement in ACM played a significant function in improving women's participation in forest management in Uganda.

Table 4.4 Men's and women's perceptions of the quality of their own participation in forest management activities

\begin{tabular}{|c|c|c|c|c|c|c|c|c|c|c|}
\hline \multirow[t]{2}{*}{ Gender } & \multicolumn{5}{|c|}{ Quality of own participation in $A C M$ sites } & \multicolumn{5}{|c|}{ Quality of own participation in non-ACM sites } \\
\hline & Poor & Moderate & Good & Very good & Undecided & Poor & Moderate & Good & Very good & Undecided \\
\hline Men & 36.6 & 32.3 & 20.2 & 6.1 & 11.1 & 46.0 & 33.6 & 12.0 & 4.4 & 7.8 \\
\hline Women & 25.0 & 42.4 & 22.3 & 13.2 & 10.7 & 43.3 & 36.4 & 13.7 & 3.0 & 13.6 \\
\hline Total & 61.5 & 74.7 & 44.5 & 19.3 & 21.8 & 89.3 & 70.0 & 25.7 & 7.4 & 51.6 \\
\hline
\end{tabular}

\section{Factors for participation in forest management in ACM versus non-ACM sites}

Factor analysis summarized the original ten participatory indicators ${ }^{2}$ in three factors, which accounted for $68.5 \%$ in ACM sites and $51.8 \%$ in non-ACM sites of the total variance of factors influencing women's participation in forest management (Table 4.5). 
96 Allan Bomuhangi et al.

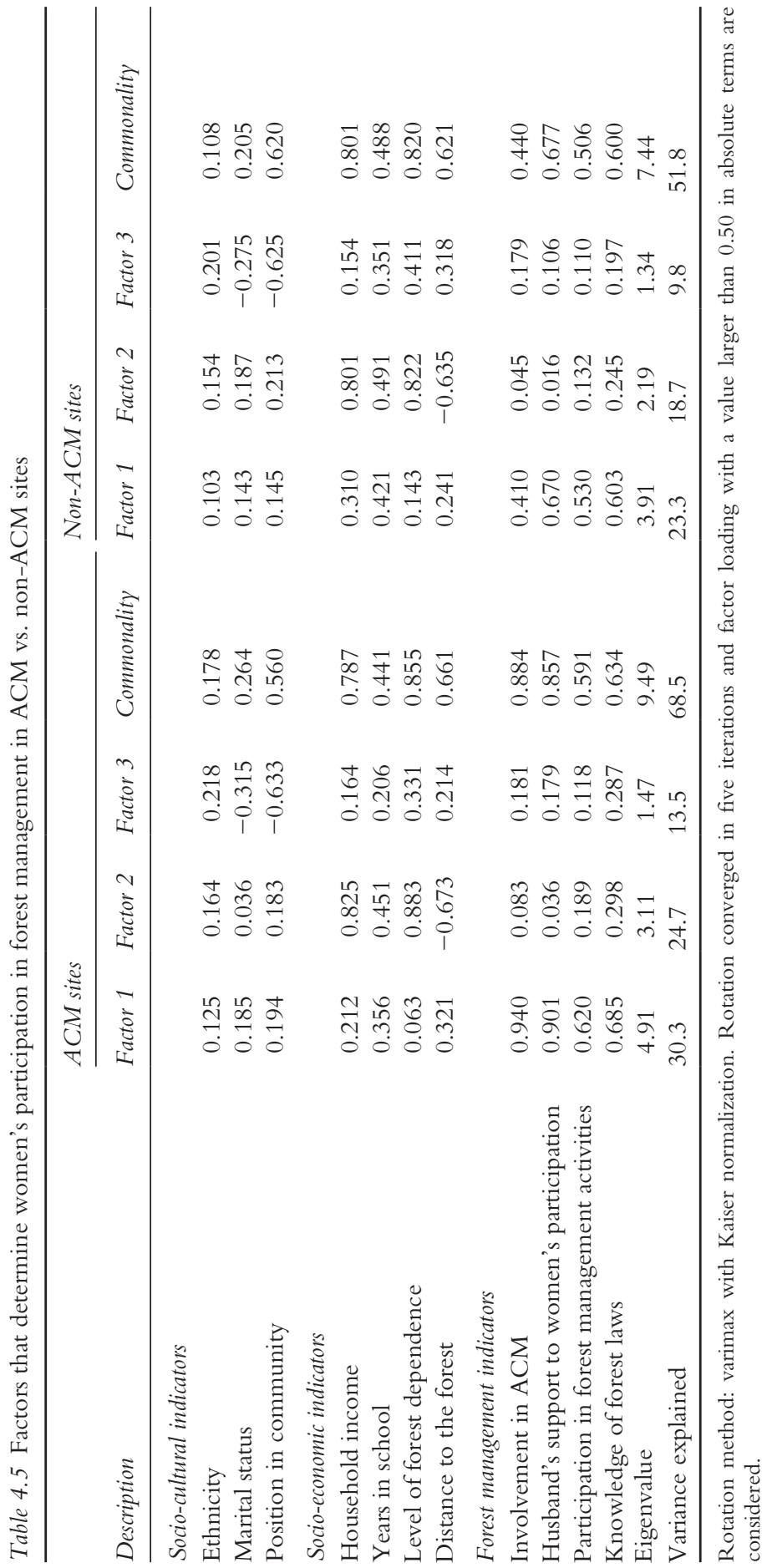


The dominant variables for the first factor (Table 4.5), which explained $30.3 \%$ and $23.4 \%$ of the variation in ACM and non-ACM sites, respectively, are mostly indicators related to inclusion in forest management. The level of participation in ACM and the husband's support to women's participation had the highest loading of 0.94 and 0.90 in ACM sites, while in non-ACM sites, husband's support and knowledge of forest laws had the highest loading of 0.67 and 0.60 , respectively. Qualitative results indicated that husband's support to women's participation increased if the husband also participated in ACM.

The dominating variables for the second factor, which explained $24.7 \%$ and $18.75 \%$ of the variation in ACM and non-ACM sites, were related to the socio-economic characteristics of the respondents. The level of dependence on forest resources had the highest loading of 0.88 and 0.82 in ACM and nonACM sites, respectively. The majority of the women were benefiting economically from the forest since it provided them with forest products for both subsistence and income. Household income had the second-highest loading with 0.83 and 0.80 in ACM and non-ACM sites, respectively. Furthermore, distance to the forest had a negative loading in both sites, suggesting that when the forest was distant, due to the various roles that women play and dangers they may experience, long-distance acts as a disincentive to participation in forest management.

The third factor explained $13.5 \%$ and $9.8 \%$ of the variation in ACM and non-ACM sites, respectively. The position of women in the community (leadership) had the highest loading of -0.63 and -0.62 , implying that low status decreased the women's ability to express themselves and voice their opinions in forest management, leading to less participation.

Contrary to Lise (2000) and Owubah et al. (2001), who argue that education influences participation in forest management and conservation, in our study, the number of years spent in school did not influence women's participation in forest management. This may be due to the fact that most of the women had reported low levels of education (mean average of 3.75 years in school).

Factor analysis revealed that men's participation in forest management was influenced by three factors that accounted for $64.8 \%$ in ACM sites and $55.8 \%$ in non-ACM sites of the total variance of factors influencing men's participation in forest management (Table 4.6). Like the female counterparts, forest management factors had the highest loading for factor 1 , followed by socioeconomic characteristics and finally socio-cultural characteristics. The status of men in the community, unlike that of women, did not have a significant role in influencing men's participation in forest management.

The marital status of men and women across both ACM and non-ACM sites had no significant positive impact on participation in forest management; however, it had a negative loading, implying that married men and women were less willing to participate in forest management than those who were single. This could mean that younger women or men are more willing to participate in and contribute to forest management. This could be related to 


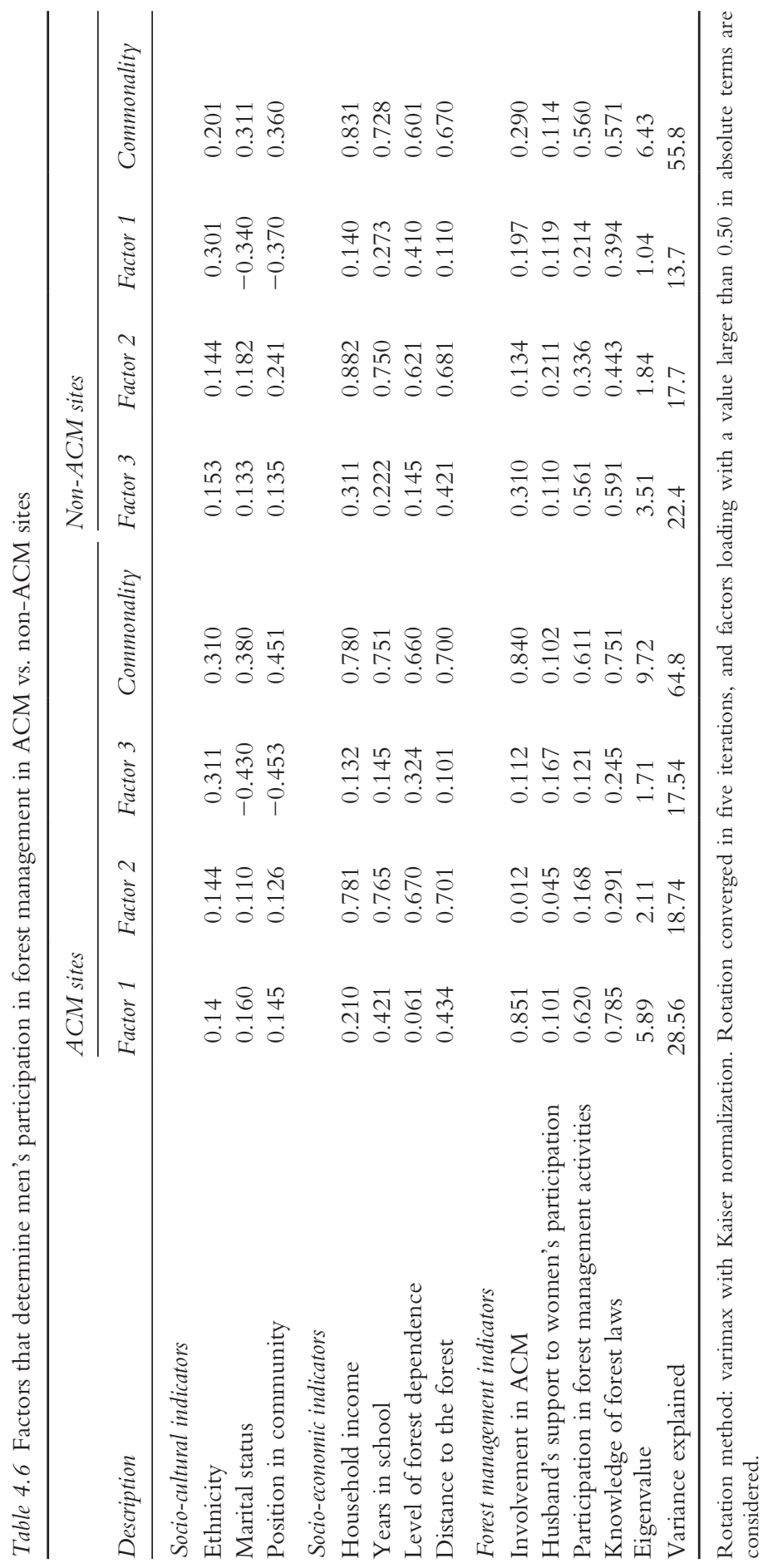


the additional workload of married members, which can reduce their time available to participate in forest management compared with single members. In addition, ethnicity, like marriage, had no significant positive impact in forest management, implying that the ethnic background of respondents did not matter in forest management participation.

\section{Dependence on forest products}

In order to obtain insights on community dependence on forest products, we investigated the forest products harvested by men and women from ACM sites and non-ACM sites (Table 4.7). While the same range of forest resources is harvested by men and women across both ACM and non-ACM study sites for most products, there was increased charcoal harvesting in non-ACM sites as compared with ACM sites. In addition, there was more harvesting of honey by women in ACM sites compared with non-ACM sites. The difference may be at least partially attributed to the stricter forest law enforcement under ACM sites. But the fact that during ACM implementation sustainable harvesting of forest products such as honey production was emphasized while destructive harvesting practices such as charcoal production were discouraged (see Chapter 5) was another important factor. Results also show evidence of marked gender specialization in the collection of forest products. Men mostly harvested the following products: poles, charcoal, honey and sand. On the other hand, women's harvesting emphasized firewood, water, herbs and craft material (Table 4.7). A chi-square test of independence was performed to examine the relation between gender and products harvested from ACM and non-ACM sites. The relationship between these variables was significant in both ACM sites $-\chi^{2}(10, \mathrm{~N}=400)=2.4, p=0.0014$, and non-ACM sites $-\chi^{2}(10, \mathrm{~N}=652)$ $=1.06, p=0.0027$. Men and women were likely to harvest different products

Table 4.7 Forest products harvested by women and men in ACM and non-ACM sites

\begin{tabular}{lcccc}
\hline \multirow{2}{*}{ Products } & \multicolumn{2}{l}{ ACM sites } & \multicolumn{2}{c}{ Non-ACM sites } \\
\cline { 2 - 3 } \cline { 5 - 5 } Women $\%$ & Men $\%$ & Women $\%$ & Men $\%$ \\
\hline Poles & 10.7 & 1.6 & 29.1 & 4.2 \\
Firewood & 5.7 & 43.8 & 5.7 & 35.4 \\
Carbon/charcoal & 6.8 & 0.5 & 22.9 & 35.4 \\
Wild animals & 6.0 & 0.0 & 4.6 & 0.0 \\
Craft materials & 1.6 & 22.3 & 2.3 & 5.4 \\
Herbs & 3.8 & 28.0 & 8.0 & 21.4 \\
Honey & 21.6 & 0.0 & 10.9 & 0.0 \\
Water & 12.3 & 8.9 & 3.4 & 34.5 \\
Sand & 12.3 & 2.2 & 5.7 & 1.2 \\
Fodder/grass & 9.6 & 8.3 & 4.6 & 0.6 \\
Fibre & 4.5 & 2.1 & 10.5 & 2.9 \\
\hline
\end{tabular}


from the forest. However, when the two site types were compared, results revealed that both ACM and non-ACM sites provided men and women with relatively similar amounts of products $\left(\chi^{2}(10, \mathrm{~N}=1052)=1.7, p=0.0033\right)$.

The results from this study support work by Sunderland et al. (2014) who report that there is significant gender differentiation in the collection of forest products - men and women play distinctive roles in the forest sector.

Having investigated the products harvested, it was important to further examine if the respondents considered the forest products to still be abundant within the forest in comparison with ten years ago. Results revealed that men and women had different opinions on the abundance of forest products (Table 4.8). Across both ACM and non-ACM sites, there is general agreement that forest resources have greatly decreased and are thus less abundant. However, when a comparison is made between the study site types, both men and women report that forest products are slightly more abundant in ACM sites than non-ACM sites. This could be attributed to a lower extraction of forest products from ACM sites compared with non-ACM sites by both men and women because of improved enforcement of forest rules, but also because of increased investment in alternative sources of livelihood-capacity as a result of ACM training.

The results also reveal that slightly more women than men were of the opinion that forest products were slightly more abundant; men considered the availability of forest products to be on the decline. This may suggest that forest products harvested by women, such as firewood, crafts material, water and herbs, remain abundant even when the forests are degraded. On the other hand, products harvested by men, such as poles, honey and timber, have become very scarce as forests have diminished. The relative perceived abundance of forest products in ACM sites may also be attributed to better conservation efforts due to ACM training and implementation.

Table 4.8 Perceptions on availability/abundance of forest resources

\begin{tabular}{|c|c|c|c|c|c|c|c|c|}
\hline \multirow[t]{3}{*}{ Products } & \multicolumn{4}{|c|}{ ACM sites } & \multicolumn{4}{|c|}{ Non- $A C M$ sites } \\
\hline & \multicolumn{2}{|c|}{ Women \% } & \multicolumn{2}{|c|}{ Men \% } & \multicolumn{2}{|c|}{ Women \% } & \multicolumn{2}{|c|}{ Men \% } \\
\hline & Yes & No & Yes & No & Yes & No & Yes & No \\
\hline Poles & 17.5 & 82.5 & 15.1 & 84.9 & 4.0 & 96 & 2.4 & 97.6 \\
\hline Firewood & 22.1 & 77.9 & 19.1 & 80.9 & 17.7 & 82.3 & 16.8 & 83.2 \\
\hline Carbon/charcoal & 2.2 & 97.8 & 1.9 & 98.1 & 2.3 & 97.7 & 16.8 & 83.2 \\
\hline Wild animals & 1.6 & 98.4 & 1.6 & 98.4 & 0.0 & 100 & 0.0 & 100 \\
\hline Craft materials & 7.9 & 92.1 & 37.1 & 62.9 & 1.1 & 98.9 & 0.6 & 99.4 \\
\hline Herbs & 12.6 & 87.4 & 12.1 & 87.9 & 10.3 & 89.7 & 11.3 & 88.7 \\
\hline Honey & 5.2 & 94.8 & 4.6 & 95.4 & 6.3 & 93.7 & 0.6 & 99.4 \\
\hline Water & 61.7 & $38 . .3$ & 13.7 & 17.6 & 13.7 & 86.3 & 13.7 & 86.3 \\
\hline Sand & 2.9 & 97.1 & 1.3 & 98.7 & 1.4 & 98.6 & 0.6 & 99.4 \\
\hline Fodder/grass & 4.1 & 95.9 & 3.8 & 96.2 & 0.0 & 100 & 0.6 & 99.4 \\
\hline Fibre & 6.3 & 93.7 & 3.0 & 97 & 2.7 & 93.3 & 2.4 & 97.6 \\
\hline
\end{tabular}




\section{Gender dimension of forest product and income use}

In order to understand how the forest contributes to the livelihoods of men and women, we first investigated how the communities use forest products. The results show that both men and women in ACM and non-ACM sites use forest products mainly to meet their domestic needs (Table 4.9). However, in ACM sites, a larger percentage of men $(33 \%)$ and women $(28 \%)$ reported using more forest products for income generation (commercial vs subsistence) as compared with non-ACM sites ( $22 \%$ men and $14 \%$ women). This could be attributed to the fact that during implementation of ACM, the community members were encouraged to participate in sustainable forest income-generating enterprises such as beekeeping for honey production and tree planting - contributing to global restoration efforts as well, on a small scale - for both domestic and commercial purposes (see Chapter 5).

Table 4.9 Gender dimensions of forest product and income use

\begin{tabular}{llllll}
\hline Use type & \multicolumn{2}{l}{ ACM sites } & & \multicolumn{2}{l}{ Non-ACM sites } \\
\cline { 2 - 3 } & Men (\%) & Women (\%) & Men (\%) & Women (\%) \\
\hline Forest product use & 67 & 82 & 78 & 86 \\
Subsistence use & 33 & 28 & 22 & 14 \\
Commercial use & 15.3 & 17.9 & 15.5 & 14.3 \\
Expenditure item & 22.1 & 23.7 & 18.3 & 20.7 \\
Food & 5.7 & 10.2 & 3.3 & 2.8 \\
Medical and school fees & 9.2 & 16.0 & 6.5 & 5.0 \\
Investments and savings & 23.5 & 12.2 & 18.5 & 8.2 \\
Mutual aid groups expenditure & & &
\end{tabular}

For those who earned income from the use of forest products, we wanted to understand use patterns of this income as this could have implications for people's participation in forest management. Results reveal that utilization of forest income is gendered in ACM and non-ACM sites. In both ACM and non-ACM sites, women spent income along the same budget lines, though we observed that women had increased capacity to spend in ACM sites as compared with non-ACM sites. This is attributed to the fact that women were not only harvesting for subsistence but were engaging and investing more in income-generating activities than in non-ACM sites. ACM was crucial in building capacity for women to engage in income-generating activities. Women also had better savings in mutual aid groups in ACM sites than their counterparts in non-ACM sites. Again, these are capacities obtained during ACM where members identified income-generating projects they felt would help meet their needs for basic goods and services and thus lower their level of dependence on the forests. Exchange visits among the ACM groups exposed participants to investment opportunities while the ACM village banking programmes allowed them to pool resources (see Chapter 5). 
Although qualitatively, it seemed that men spent most of their forest income on personal expenditures (as has been observed elsewhere) and women, on medicines, school fees and food, this was not borne out by our statistical tests. A chi-square test of independence was performed to examine the relation between gender and use of forest income within ACM and non-ACM sites. The relation between these variables was not significant: $\chi^{2}(4, N=400)=4.3$, $p=0.22$ in ACM; and $\chi^{2}(4, \mathrm{~N}=652)=6.9, p=0.37$ in non-ACM sites. In fact, both women and men contributed to the wellbeing of the family, along the same budget items. The results of this study suggest that forests, in addition to being important sources of subsistence foods and materials, make a significant contribution to rural household income and consequently to poverty reduction. However, the per cent contribution of income from the sale of forest produce to general household income was beyond the scope of this study.

\section{Conclusions}

Our findings indicate that factors related to forest management itself are the most important determinants of men's and women's participation in forest management in Uganda. More women in ACM sites reported enhanced participation and quality of participation in forestry management activities as compared with women in non-ACM sites. We consider participatory forest management approaches such as ACM as crucial for enhancing women's participation, particularly those whose livelihoods are directly and highly impacted by the forest. Additionally, women's participation in forest management is enhanced by participatory forest management approaches that open up public forested spaces as opposed to private forested spaces, implying that the probability of women participating at the community level (in community forests) is higher than that at the household level.

We also found that men's and women's participation in forest management can be influenced by their socio-cultural and socio-economic characteristics such as status in their community, income and level of dependence on forest resources. Women's personal and household attributes combined with sociocultural norms and values may constrain or enhance their participation in forest management in Uganda despite their participation in ACM.

Lastly, the study reveals that there is a marked gender specialization in the collection of forest products from both ACM and non-ACM sites. While there is no significant difference between the products harvested from ACM and non-ACM sites, in each of these sites, men and women harvested different forest products; men and women also both harvested forest produce for subsistence and sale. However, more women in ACM sites harvested forest produce for income generation compared with women in non-ACM sites.

\section{Policy recommendations}

These results lead us to several policy recommendations: first, in order to increase men's and women's participation in forest management, we recommend that 
participatory forest management initiatives such as ACM be institutionalized and implemented throughout the country. Forest adjacent communities should enter into collaborative forest management arrangements with the forest owners/managers (national forest authority, local government or the private forest owners) or be facilitated to form tree-planting groups or associations by NGOs and local government forestry officials. The latter kinds of activities could also contribute to more benign attempts to restore forests, in line with global efforts to do so more collaboratively (e.g., Butler and Schultz 2019; Mansourian 2020). The process should be simplified, adaptive and fast-tracked in order to increase the number of communities with collaborative forest management agreements.

Second, our study shows that the level of dependence on forest resources provides an incentive for both men and women to participate in forest management. However, present forest law allows limited use rights to forest adjacent communities. They can only legally harvest dry dead branches of trees for firewood in "reasonable quantities." Thus, communities adjacent to rich forest resources are often poor. We recommend that the withdrawal and exploitation rights of these communities be improved but regulated so that they can exploit forest resources to improve their livelihoods on a sustainable basis through collaborative forest management approaches.

\section{Acknowledgements}

We would like to thank all the communities in our study sites who cooperated with us by providing information for the study. We are very grateful to Anne Larson and the late Esther Mwangi, both of CIFOR and the research team in Nicaragua, for their valuable input in the preparation of the proposal and study instruments. We wish to express our heartfelt gratitude to the Austrian Development Agency (ADA) for providing the funds for this study.

\section{Notes}

1 CIFOR's approach is described in a number of publications, archived at https://www2 .cifor.org/acm/.

2 Level of husband's support, education/years in school, participation in ACM, distance to forest, dependence on forest resources, position/status of women in community, ethnicity, household income, knowledge of laws and policy and marital status.

\section{References}

Araral, E. J. 2009. "What Explains Collective Action in the Commons? Theory and Evidence from the Philippines." World Development 37: 687-697.

Banana, Abwoli Y., Paul O. Ongugo, W. Gombya-Ssembajjwe, Tadesse W. Gole, Fayera Senbeta, Justine Namaalwa, Emannuel Luoga, Joseph Bahati, L. A. Mbwaambo, and Franz W. Gatzweiler. 2013. "Forest Governance Reforms in East Africa: A Comparative Analysis of Institutions, Livelihoods and Forest Sustainability Outcomes.” In Institutional and Livelihood Changes in East African Forest Landscapes: Decentralization and Institutional Change for Sustainable Forest Management in Uganda, Kenya, Tanzania and Ethiopia, edited by F. Gatzweiler, 17-48. Frankfurt am Main: Peter Lang. 
Banana, Abwoli Y., Mohamed Bukenya, Eusobio Arinaitwe, Betty Birabwa, and Sylvester Ssekindi. 2012. Gender, Tenure and Community Forests in Uganda. Bogor, Indonesia: CIFOR.

Bryman, A., and D. Cramer. 2005. Quantitative Data Analysis with SPSS12 and 13: A Guide for Social Scientists. East Sussex: Routledge.

Butler, William H., and Courtney A. Schultz, eds. 2019. A New Era for Collaborative Forest Management: Policy and Practice Insights from the Collaborative Forest Landscape Restoration Program. London: Earthscan/Routledge.

Dolisca, F., D. R. Carter, J. M. McDaniel, D. A. Shannon, and C. M. Jolly. 2006. "Factors Influencing Farmers' Participation in Forestry Management Programs: A Case Study from Haiti." Forest Ecology and Management 236: 324-331.

Government of Uganda. 2001. The Uganda Forest Policy 2001. Kampala, Uganda: Ministry of Water, Lands and Environment.

Government of Uganda. 2016. Environment and Natural Resources Sub-Sector Gender Mainstreaming Strategy 2016-2021. Kampala, Uganda: Ministry of Water and Environment.

Kaiser, H. 1974. "An Index of Factorial Simplicity.” Psychometrika 39: 31-36.

Lee, Bandy X., Finn Kjaerulf, Shannon Turner, Larry Cohen, Peter D. Donnelly, Robert Muggah, Rachel Davis, et al. 2016. "Transforming Our World: Implementing the 2030 Agenda Through Sustainable Development Goal Indicators." Journal of Public Health Policy 37 (1) Supplement 1: 13-31.

Lise, Wietze. 2000. “Factors Influencing People's Participation in Forest Management in India." Ecological Economics 34 (3): 379-392.

Mansourian, Stephanie. 2020. Enabling Factors to Scale Up Forest Landscape Restoration: The Roles of Governance and Economics: Full Report with Case Studies. Berlin, Germany: WWF and IUFRO.

Maskey, V., T. G. Gebremedhin, and T. J. Dalton. 2006. "Social and Cultural Determinants of Collective Management of Community Forest in Nepal." Journal of Forest Economics 11: 261-274.

Mukasa, C., Alice Tibazalika, E. Mwangi, A. Y. Banana, and K. Evans. 2016. Adaptive Collaborative Management: A Simplified Guide for Practitioners. Bogor, Indonesia: CIFOR.

Ostrom, E. 1990. Governing the Commons: The Evolution of Institutions for Collective Action. New York: Cambridge University Press.

Owubah, Charles E., Dennis C. Le Master, J. Michael Bowker, and John G. Lee. 2001. "Forest Tenure Systems and Sustainable Forest Management: The Case of Ghana." Forest Ecology and Management 149 (1-3): 253-264.

Sunderland, Terry, Ramadhani Achdiawan, Arild Angelsen, Ronnie Babigumira, Amy Ickowitz, Fiona Paumgarten, Victoria Reyes-García, and Gerald Shively. 2014. "Challenging Perceptions About Men, Women, and Forest Product Use: A Global Comparative Study.” World Development 64: S56-S66.

Uganda Bureau of Statistics. 2013. Statistical Abstract. Kampala: Uganda Bureau of Statistics. 